\title{
THE RESPIRATORY RESPONSE TO CARBON DIOXIDE IN HEALTH AND IN EMPHYSEMA
}

\author{
By D. BRODOVSKY, J. A. MACDONELL AND R. M. CHERNIACK * \\ (From the Department of Medicine, University of Manitoba, and the Clinical Investigation \\ Units, Winnipeg General Hospital, and Deer Lodge Hospital, Winnipeg, Manitoba)
}

(Submitted for publication October 6, 1959; accepted January 8, 1960)

The tension of carbon dioxide in the cells of the medullary respiratory center stimulates it to transmit efferent nervous impulses to the muscles of respiration. These, in turn, perform mechanical work upon the lung and thorax, and result in the complex movement of air known as ventilation. Ideally, therefore, the stimulus (tissue carbon dioxide tension) and the response (efferent impulses) should be measured in order to assess the response of the respiratory center to carbon dioxide.

Arterial carbon dioxide tension is generally considered to be a satisfactory approximation of the stimulus delivered to the respiratory center, but the response is far more difficult to measure. While most investigations have reported the response in terms of ventilation (1-3), this may be modified by the ventilatory capacity and the degree of airway obstruction (4). The response of the respiratory muscles, therefore, should be a more accurate measure of respiratory center activity. This can be assessed by measuring the total amount of mechanical work done by these muscles.

There is no known method of directly measuring the total mechanical work done by the respiratory muscles. However, if the oxygen consumption (or energy cost) of the respiratory muscles and the efficiency with which the muscles utilize the oxygen are known, the total mechanical work of breathing may be calculated $(5,6)$.

The purpose of this paper is to report the respiratory response to carbon dioxide, in terms of the total mechanical work performed by the respiratory muscles, in normal subjects and in patients with chronic pulmonary emphysema.

\section{METHOD}

Studies were performed on 12 normal subjects and 10 patients with emphysema, whose physical characteristics and pulmonary function assessment are shown in Table

* Markle Scholar in Medical Sciences.
I. Vital capacities, expiratory flow rates and maximum breathing capacities were measured on a $9 \mathrm{~L}$ Collins respirometer, with the valves and carbon dioxide absorber removed. The maximum of at least 3 determinations was chosen.

All normal subjects had excellent ventilatory function and showed no clinical or radiological evidence of cardiopulmonary disease.

The diagnosis of emphysema was based on the clinical history and physical examination, as well as on radiological and spirographic evidence. The selection of the patients studied was dependent upon their ability to tolerate the prolonged period of inactivity and the severe respiratory effort associated with breathing through an added inspiratory resistance. All patients with emphysema showed marked obstruction to expiratory air flow and reduction of the maximum breathing capacity. Hypoxia was present in all, and carbon dioxide retention in five, while breathing room air at rest. On the other hand, hypercapnia was present in all when breathing 100 per cent oxygen. In addition, the oxygen cost of an increase in ventilation was high, and the efficiency of the respiratory muscles was low.

The subjects were studied in the postabsorptive state, and rested in a comfortable easy chair for one hour before any measurements were made. An indwelling Riley needle was inserted into the brachial artery of the patients with emphysema. All subjects then breathed to and from a closed-circuit spirometer, through varying lengths of dead space for at least 20 minutes. During the last 7 to 10 minutes, records of ventilation and oxygen consumption were obtained. A rest period of 10 to 15 minutes was allowed between measurements.

Oxygen consumption and ventilation were measured by a method previously described (5-7). Increased levels of ventilation were achieved by interposing dead space consisting of thick-walled rubber tubing $(3 \mathrm{~cm}$ ID) between the spirometer and the subject. Minute ventilation was expressed in liters per minute BTPS and oxygen consumption in milliliters per minute STPD.

An end-tidal sampler, modified from Rahn and Otis (8), was incorporated into the breathing valve, and endtidal air was analyzed for carbon dioxide, by means of a rapid infrared Liston-Becker gas analyzer. The endtidal carbon dioxide tension, used as an index of arterial carbon dioxide in the normal subjects, ${ }^{1}$ was determined

1 Hereafter, for the sake of simplicity, all measurements of carbon dioxide tension will be referred to as arterial carbon dioxide tension. 
TABLE I

Physical characteristics and pulmonary function of normal and emphysematous subjects *

\begin{tabular}{|c|c|c|c|c|c|c|c|c|c|c|c|c|c|}
\hline \multirow{2}{*}{$\begin{array}{l}\text { Subject } \\
\text { no. and } \\
\text { sex }\end{array}$} & \multirow[b]{2}{*}{ Age } & \multirow[b]{2}{*}{ Ht. } & \multirow[b]{2}{*}{ BSA } & \multicolumn{2}{|c|}{ Vital capacity } & \multicolumn{2}{|c|}{$\begin{array}{l}\text { Maximum } \\
\text { breathing } \\
\text { capacity }\end{array}$} & \multirow[b]{2}{*}{$\begin{array}{c}\text { Arterial } \\
\mathrm{pO}_{2}\end{array}$} & \multicolumn{2}{|c|}{$\underset{\mathrm{pCO}_{2}}{\text { Arterial }}$} & \multirow[b]{2}{*}{$\begin{array}{l}\text { Effici- } \\
\text { ency }\end{array}$} & \multirow[b]{2}{*}{$\mathrm{O}_{2} \cos \mathrm{t}$} & \multirow[b]{2}{*}{$\begin{array}{c}\text { Resting } \\
\text { work }\end{array}$} \\
\hline & & & & & $\begin{array}{c}\% \\
\text { Pred. }\end{array}$ & & $\begin{array}{c}\% \\
\text { Pred. }\end{array}$ & & $\begin{array}{c}\text { Room } \\
\text { air }\end{array}$ & $\begin{array}{c}100 \% \\
\mathrm{O}_{2}\end{array}$ & & & \\
\hline & yrs & $\mathrm{cm}$ & $m^{2}$ & $L$ & & $L / \min$ & & $m m \mathrm{Hg}$ & & & $\%$ & $m l / L$ & $\underset{\mathrm{min} / \mathrm{m}^{2}}{\mathrm{~kg}-\mathrm{m} /}$ \\
\hline $1 \mathrm{~F}$ & 22 & 178 & 1.83 & 4.42 & 125 & 131 & 122 & & & 38 & 10.0 & 0.9 & 0.8 \\
\hline $2 \mathrm{M}$ & 21 & 189 & 2.05 & 5.94 & 124 & 205 & 140 & & & 39 & 10.2 & 2.7 & 2.6 \\
\hline $3 \mathrm{~F}$ & 19 & 165 & 1.72 & 3.84 & 116 & 125 & 125 & & & 39 & 10.9 & 0.6 & 0.7 \\
\hline $4 \mathrm{M}$ & 25 & 179 & 1.99 & 5.17 & 118 & 220 & 166 & & & 40 & 5.9 & 1.3 & 0.6 \\
\hline $5 \mathrm{M}$ & 26 & 183 & 1.93 & 5.45 & 121 & 173 & 128 & & & 41 & 9.1 & 1.1 & 1.0 \\
\hline $6 \mathrm{M}$ & 43 & 170 & 1.87 & 4.76 & 125 & 186 & 181 & & & 41 & 6.5 & 0.9 & 0.6 \\
\hline $7 \mathrm{M}$ & 24 & 178 & 2.0 & 6.20 & 162 & 192 & 160 & & & 41 & 7.9 & 0.7 & 0.3 \\
\hline $8 \mathrm{M}$ & 29 & 193 & 2.21 & 6.88 & 143 & 160 & 115 & & & 42 & 6.5 & 1.1 & 0.6 \\
\hline $9 \mathrm{M}$ & 25 & 173 & 1.79 & 4.98 & 120 & 182 & 145 & & & 42 & 8.1 & 1.3 & 1.2 \\
\hline $10 \mathrm{M}$ & 34 & 180 & 1.90 & 6.20 & 152 & 182 & 152 & & & 42 & 9.3 & 2.5 & 1.7 \\
\hline $11 \mathrm{M}$ & 26 & 182 & 1.98 & 5.50 & 125 & 143 & 108 & & & 43 & $8.0^{\circ}$ & 2.0 & 2.1 \\
\hline $12 \mathrm{M}$ & 22 & 178 & 1.90 & 5.40 & 121 & 286 & 214 & & & 46 & 7.9 & 0.5 & 0.4 \\
\hline $13 \mathrm{M}$ & 57 & 180 & 1.97 & 2.78 & 71 & 49 & 48 & 47 & 38 & 50 & 1.6 & 3.2 & 0.5 \\
\hline $14 \mathrm{M}$ & 69 & 180 & 1.76 & 2.93 & 80 & 42 & 47 & 52 & 40 & 70 & 2.1 & 2.8 & 0.8 \\
\hline $15 \mathrm{M}$ & 46 & 169 & 1.68 & 2.34 & 64 & 27 & 26 & 57 & 41 & 47 & 4.3 & 3.3 & 1.5 \\
\hline $16 \mathrm{M}$ & 61 & 179 & 1.78 & 2.73 & 71 & 18 & 18 & 68 & 41 & 51 & 2.0 & 3.9 & 1.3 \\
\hline $17 \mathrm{M}$ & 63 & 173 & 1.68 & 1.69 & 48 & 17 & 19 & 49 & 43 & 57 & 1.5 & 9.1 & 1.9 \\
\hline $18 \mathrm{M}$ & 60 & 175 & 1.65 & 1.83 & 49 & 11 & 12 & 48 & 51 & 51 & 0.7 & 14.2 & 1.1 \\
\hline $19 \mathrm{M}$ & 73 & 155 & 1.31 & 1.64 & 60 & 20 & 40 & 58 & 55 & 59 & 1.0 & 8.4 & 0.9 \\
\hline $20 \mathrm{M}$ & 53 & 173 & 1.70 & 2.05 & 57 & 20 & 21 & 62 & 56 & 57 & 1.9 & 4.9 & 1.2 \\
\hline $21 \mathrm{M}$ & 69 & 179 & 1.86 & 1.64 & 47 & 27 & 31 & 36 & 60 & 63 & 2.2 & 6.1 & 1.2 \\
\hline $22 \mathrm{M}$ & 43 & 168 & 1.72 & 3.64 & 98 & 28 & 27 & 69 & 61 & 61 & 2.1 & 4.2 & 1.5 \\
\hline
\end{tabular}

* Subjects 1 through 12 are normal; Subjects 13 through 22 are emphysematous.

for 1 to 2 minutes immediately before and after the recording period, so that for all calculations, no allowance had to be made for the air passing through the analyzer. No difference was noted between the readings taken before and after the recording period.

An arterial blood sample was drawn from the emphysematous subjects before beginning the experiment while they were breathing ambient air, and over the fourth to seventh minutes of each recording period. Arterial gas tensions were measured by the method of Riley, Proemmel and Franke (9), as modified by Brinkman, Johns, Donoso and Riley (10).

Measurements of ventilation, oxygen consumption and $\mathrm{pCO}_{2}$ were made at rest and at three levels of increased ventilation, except in Subjects 6,17 and 19. In these three patients, measurements were made at two levels of increased ventilation.

The oxygen cost of increased ventilation was calculated by plotting oxygen consumption against minute ventilation, and visually drawing the best-fitting straight line. The slope of this line, in milliliters per liter expressed the oxygen cost of increased ventilation. The oxygen consumption of the respiratory muscles at any level of ventilation could then be calculated by multiplying the oxygen cost by the observed ventilation.

The "efficiency" of the respiratory muscles was obtained by measuring the increase in oxygen consumption associated with an added respiratory work load of known magnitude, as previously described (5). The in- crease in respiratory work was achieved by having the subject inspire through a wide-bore metal pipe, projecting under a water seal. There was no change in resting level while breathing through the added resistance in either the normal or emphysematous subjects. In the latter, there was a slight increase in ventilation, however. This necessitated comparison with the oxygen consumption at an equivalent ventilation. This could be derived from the line relating ventilation and oxygen consumption when there was no added work load. Since the oxygen consumption before, and while breathing through the water seal, were compared at equivalent ventilations, and there was no change in resting level, the efficiency of the respiratory muscles for handling added work could be calculated.

Since the efficiency of the respiratory apparatus has been shown to be essentially the same at various levels of ventilation (5-7), the total mechanical work of breathing could be calculated at any level of ventilation. This was done by multiplying the observed efficiency by the mechanical energy equivalent of the oxygen consumption of the respiratory apparatus, and was expressed in kilogram-meters per minute.

\section{RESULTS}

Figure 1 presents the effect of changes in arterial carbon dioxide tension on the minute ventilation in the normal and emphysematous sub- 


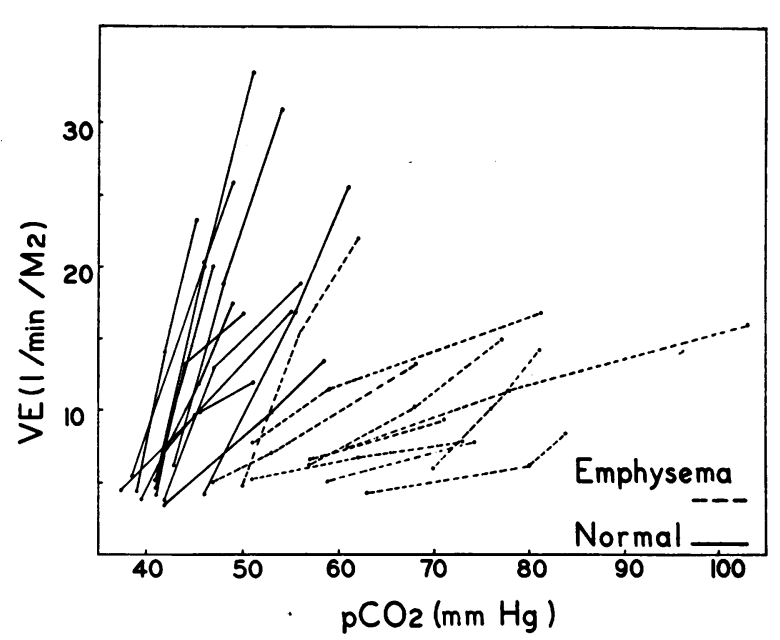

Fig. 1. The effect of Changes in arterial $\mathrm{PCO}_{2}$ ON the MiNUte ventilation IN 12 NORMal SUbJeCtS AND 10 PATIENTS WITH PULMONARY EMPHYSEMA.

jects. It can be noted that although there was a wide range of slopes of ventilatory response in the normal group, the mean being $1.70 \mathrm{~L}$ per mm $\mathrm{Hg} \mathrm{pCO}_{2}$ (range 0.59 to 3.18 ), the emphysematous subjects tended to have a markedly diminished ventilatory response to carbon dioxide, the mean slope being $0.77 \mathrm{~L}$ per $\mathrm{mm} \mathrm{Hg} \mathrm{pCO}_{2}$ (range 0.11 to 3.57 ).

The effect of changes in arterial carbon dioxide tension on the oxygen consumption in the normal and emphysematous subjects is presented in Figure 2. It can be seen that the slopes of the oxygen consumption lines tended to be similar in the

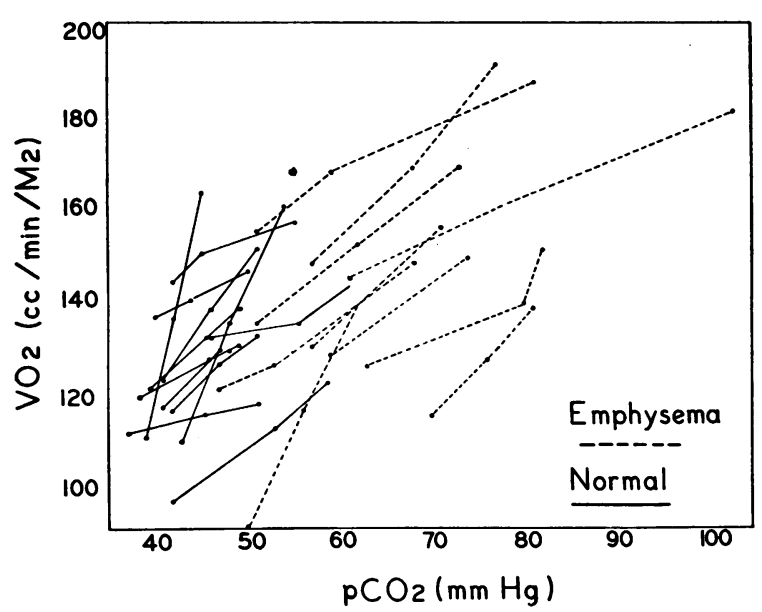

Fig. 2. The efFect of Changes in ARTERIAL $\mathrm{PCO}_{2}$ ON THE OXYGEN CONSUMPTION IN 12 NORMAL SUBJECTS AND 10 PATIENTS WITH PULMONARY EMPHYSEMA.

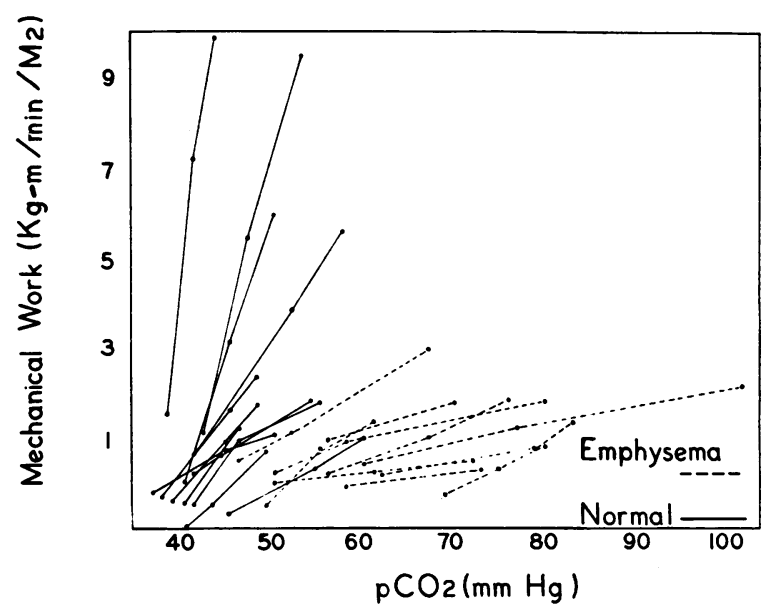

Fig. 3. The efFect of Changes in ARTerial PCO, ON THE TOTAL MECHANICAL WORK OF BREATHING IN 12 NORMAL SUBJECTS AND 10 PATIENTS WITH PULMONARY EMPHYSEMA.

normal and emphysematous subjects. The mean slope was $2.33 \mathrm{ml}$ per $\mathrm{mm} \mathrm{Hg} \mathrm{pCO}_{2}$ (range 0.52 to 8.69 ) in the normals and $1.79 \mathrm{ml}$ per $\mathrm{mm} \mathrm{Hg}$ (range 0.87 to 4.84 ) in the patients with emphysema.

In Figure 3, the effects of changes in arterial carbon dioxide tension on the total mechanical work of breathing are shown. It can be seen that although there was some similarity between the slopes of the response lines of mechanical work of breathing in the two groups, the mechanical work response to an increase in arterial carbon
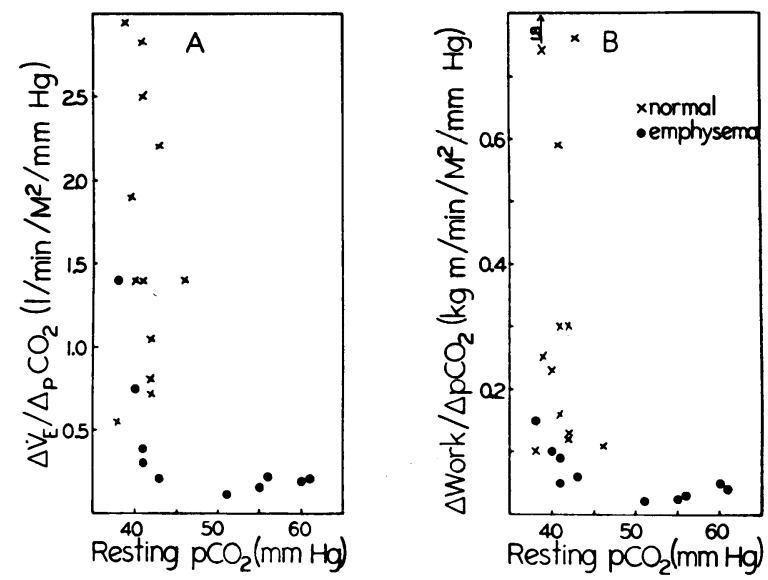

Fig. 4. The relationship Between Resting $\mathrm{PCO}_{2}$ WHILE BREATHING AIR, AND THE SLOPES OF THE VENTILATORY RESPONSE, A, AND THE TOTAL MECHANICAL WORK RESPONSE, B, TO CARBON DIOXIDE IN NORMAL AND EMPHYSEMATOUS SUBJECTS. 
TABLE II

The effect of artificial airway obstruction on ventilatory function

\begin{tabular}{|c|c|c|c|c|c|c|c|c|c|c|c|c|}
\hline \multirow[b]{2}{*}{ Subject } & \multicolumn{2}{|c|}{$\mathrm{pCO}_{2}$} & \multicolumn{2}{|c|}{ Ventilation } & \multicolumn{2}{|c|}{$\begin{array}{l}\text { Maximum } \\
\text { breathing } \\
\text { capacity }\end{array}$} & \multicolumn{2}{|c|}{ Efficiency } & \multicolumn{2}{|c|}{ Oxygen cost } & \multicolumn{2}{|c|}{$\underset{\substack{\text { mechanical } \\
\text { work }}}{\text { Resting }}$} \\
\hline & $\mathrm{N}^{*}$ & Obs.† & $\mathbf{N}$ & $\overline{\text { Obs. }}$ & $\mathbf{N}$ & Obs. & $\mathbf{N}$ & Obs. & $\mathbf{N}$ & $\overline{\text { Obs. }}$ & $\mathrm{N}$ & $\overline{\text { Obs. }}$ \\
\hline & \multicolumn{2}{|c|}{$m m \mathrm{Hg}$} & \multicolumn{2}{|c|}{$L / \min / m^{2}$} & \multicolumn{2}{|c|}{$L / \min$} & $\%$ & $\%$ & \multicolumn{2}{|c|}{$m l / L$} & \multicolumn{2}{|c|}{$k g-m / \min / m^{2}$} \\
\hline $\begin{array}{r}4 \\
5 \\
6 \\
12\end{array}$ & $\begin{array}{l}40 \\
41 \\
41 \\
46\end{array}$ & $\begin{array}{l}41 \\
39 \\
39 \\
44\end{array}$ & $\begin{array}{l}3.9 \\
5.1 \\
5.1 \\
4.4\end{array}$ & $\begin{array}{l}4.1 \\
4.3 \\
5.3 \\
4.4\end{array}$ & $\begin{array}{l}220 \\
173 \\
186 \\
286\end{array}$ & $\begin{array}{r}77 \\
58 \\
67 \\
104\end{array}$ & $\begin{array}{l}5.9 \\
9.1 \\
6.5 \\
7.9\end{array}$ & $\begin{array}{l}4.8 \\
5.2 \\
2.4 \\
3.6\end{array}$ & $\begin{array}{l}1.3 \\
1.1 \\
0.9 \\
0.5\end{array}$ & $\begin{array}{l}4.1 \\
2.8 \\
2.8 \\
2.7\end{array}$ & $\begin{array}{l}0.6 \\
1.0 \\
0.6 \\
0.4\end{array}$ & $\begin{array}{l}1.9 \\
1.6 \\
0.8 \\
1.0\end{array}$ \\
\hline Mean & 42 & 40.8 & 4.6 & 4.5 & 216 & 75 & 7.4 & 4.0 & 1.0 & 3.1 & 0.7 & 1.3 \\
\hline
\end{tabular}

* Resting breathing.

† Obstructed breathing.

dioxide tension was lower in most of the emphysematous subjects. The mean slope was $0.42 \mathrm{~kg}-\mathrm{m}$ per minute per $\mathrm{m}^{2}$ per $\mathrm{mm} \mathrm{Hg} \mathrm{pCO}_{2}$ (range 0.11 to 1.84 ) in the normals, and $0.07 \mathrm{~kg}-\mathrm{m}$ per minute per $\mathrm{m}^{2}$ per $\mathrm{mm} \mathrm{Hg} \mathrm{pCO}_{2}$ (range 0.02 to 0.17 ) in the patients with emphysema.

The relationship between the resting arterial $\mathrm{pCO}_{2}$ while breathing ambient air and the slopes of the stimulus response lines of the normal and emphysematous subjects is shown in Figure 4. The slopes of the ventilatory response are plotted in $\mathrm{A}$, while the slopes of the total mechanical work response are plotted in B. It can be seen that the slopes of both the ventilatory and total mechanical work response lines tended to be diminished in the patients with emphysema, particularly in those who were hypercapnic at rest.

Since it has been shown that airway resistance will reduce the ventilatory response to carbon dioxide (4), it was desirable to ascertain the effect of obstruction on the oxygen consumption and mechanical work of breathing response to changes in arterial carbon dioxide. The entire procedure was therefore repeated with four normal subjects, at a different sitting, while breathing through an artificial airway obstruction. The obstruction consisted of a metal pipe ( $3 \mathrm{~cm}$ ID), which was packed with glass wool, and which offered a resistance of $0.3 \mathrm{~cm} \mathrm{H}_{2} \mathrm{O}$ per $\mathrm{L}$ per second at flow rates between 10 and $100 \mathrm{~L}$ per second.

Table II shows the effect of the artificial airway obstruction on pulmonary function in the four normal subjects. It can be seen that there was no change in resting arterial carbon dioxide tension or minute ventilation while breathing through the obstruction. On the other hand, it can also be seen that the maximum breathing capacity and the calculated efficiency of the respiratory apparatus were reduced, while the resting total mechanical work of breathing and the oxygen cost of increased ventilation rose markedly.

The influence of airway obstruction on the

TABLE III

The effect of artificial airway obstruction on respiratory response to carbon dioxide

\begin{tabular}{|c|c|c|c|c|c|c|}
\hline \multirow[b]{2}{*}{ Subject } & \multicolumn{2}{|c|}{$\Delta \mathrm{VE} / \Delta \mathrm{pCO}_{2} *$} & \multicolumn{2}{|c|}{$\Delta \mathrm{VO}_{2} / \Delta \mathrm{pCO}_{2} \dagger$} & \multicolumn{2}{|c|}{$\Delta$ Work/ $\Delta \mathrm{pCO}_{2} \ddagger$} \\
\hline & N\& & Obs.\| & $\mathbf{N}$ & Obs. & $\mathbf{N}$ & Obs. \\
\hline & \multicolumn{2}{|c|}{$L / \mathrm{min} / \mathrm{m}^{2} / \mathrm{mm} \mathrm{Hg}$} & \multicolumn{2}{|c|}{$\mathrm{ml} / \mathrm{min} / \mathrm{m}^{2} / \mathrm{mm} \mathrm{Hg}$} & \multicolumn{2}{|c|}{$\mathrm{kg}-\mathrm{m} / \mathrm{min} / \mathrm{m}^{2} / \mathrm{mm} \mathrm{Hg}$} \\
\hline $\begin{array}{c}4 \\
5 \\
6 \\
12 \\
\text { Mean }\end{array}$ & $\begin{array}{l}1.37 \\
2.90 \\
2.48 \\
1.37 \\
2.03\end{array}$ & $\begin{array}{l}0.51 \\
1.72 \\
1.41 \\
0.58 \\
1.06\end{array}$ & $\begin{array}{l}1.76 \\
2.78 \\
2.08 \\
0.53 \\
1.79\end{array}$ & $\begin{array}{l}2.02 \\
5.20 \\
3.84 \\
1.53 \\
3.12\end{array}$ & $\begin{array}{l}0.23 \\
0.59 \\
0.27 \\
0.11 \\
0.30\end{array}$ & $\begin{array}{l}0.22 \\
0.52 \\
0.20 \\
0.12 \\
0.27\end{array}$ \\
\hline
\end{tabular}

* Change in ventilation per $\mathrm{mm} \mathrm{Hg} \mathrm{pCO}_{2}$.

$\dagger$ Change in oxygen consumption per $\mathrm{mm} \mathrm{Hg} \mathrm{pCO}_{2}$.

$\ddagger$ Change in mechanical work per $\mathrm{mm} \mathrm{Hg} \mathrm{pCO}$.

$\$$ Resting breathing.

II Obstructed breathing. 
respiratory responses to carbon dioxide is shown in Table III. It can be seen that the slope of the ventilatory response to carbon dioxide was sharply reduced by an airway obstruction, while the slope of the oxygen consumption response to carbon dioxide was increased. On the other hand, the slope of the total mechanical work response to carbon dioxide was not altered by the introduction of an airway obstruction.

\section{DISCUSSION}

It is apparent that the conclusions which can be drawn from this paper are dependent upon the interpretation of the data which have been presented. Thus, if increments in ventilation or mechanical work are accepted as the response of the respiratory system to changes in carbon dioxide, it can be concluded that the sensitivity of the respiratory system was diminished in patients with emphysema. On the other hand, if increments in oxygen consumption are regarded as the response of the respiratory system, it can be concluded that there was no alteration in sensitivity of the respiratory system in the emphysematous subjects. For reasons outlined below, we are in favor of the theory that the response of the respiratory system is best reflected by the increments in total mechanical work done by the respiratory muscles.

In any study of the response of the respiratory system to carbon dioxide, consideration should be given to both the minimum stimulus necessary to evoke a response, and the slope of the stimulus-response line. No measurements of threshold stimulus were made in this study. Nevertheless, the finding of hypercapnia in the presence of a normal resting minute ventilation and total mechanical work of breathing, suggests that the threshold of response was altered in the patients with emphysema.

The finding that the administration of oxygen led to hypercapnia even in those patients who were normocapnic at rest while breathing room air is surprising and difficult to explain. Richards, Fritts and Davis (11) have shown that while the arterial $\mathrm{pCO}_{2}$ rose in patients with emphysema who were breathing oxygen-enriched gas mixtures, the slope of the stimulus-response line of any one subject was unaltered. In the present paper, the ventilatory and total mechanical work response lines were diminished from the normal in almost all of the emphysematous subjects, particularly those who were hypercapnic at rest even while breathing room air. This suggests that the sensitivity of the respiratory system was diminished.

The fact that both a diminished ventilatory and total mechanical work response to carbon dioxide were found in patients with emphysema, suggests no advantage to the measurement of the total mechanical work response as an index of the sensitivity of the respiratory system. However, the data presented in this paper, and those of Cherniack and Snidal (4), indicate that the slope of the ventilatory response to carbon dioxide can be altered by breathing through an artificial airway resistance. Moreover, the ventilatory response to carbon dioxide can be increased after the administration of nebulized bronchodilator in emphysematous patients (4). Unless the respiratory center sensitivity was changed acutely in these subjects, these findings suggest that increments in ventilation are an inadequate expression of respiratory center response.

The data presented also indicate that the change in oxygen uptake, in response to a rise in arterial carbon dioxide tension, is similar in normal and emphysematous subjects. This is in agreement with the data of Richards and associates (11), whose interpretation was that the response of the respiratory center and the muscles of patients with emphysema was essentially normal. However, the amount of oxygen consumed by the respiratory muscles for a given unit of work done will depend upon the efficiency of the respiratory muscles. Thus, when comparing the response of the respiratory system in two groups of individuals, the increments in oxygen consumption may be compared only when the efficiency of the respiratory muscles is similar in the two groups being compared. It is important to differentiate between energy cost and energy output in any mechanical or biological system, where efficiencies may vary. The data presented in this paper indicate that the efficiency of the respiratory muscles was considerably lower than normal in the patients with emphysema. Thus, the work output of the respiratory apparatus in response to changes in $\mathrm{CO}_{2}$ was considerably lower than normal in these patients. 
In addition, the data presented in this paper indicate that the slopes of ventilation and oxygen consumption increments in response to carbon dioxide could be altered while breathing through an artificial airway obstruction, while the slope of the total mechanical work response was unaltered. Assuming no acute change in respiratory center sensitivity while breathing through the obstruction, it may be presumed that the center will respond in the same way to changes in carbon dioxide whether or not obstruction is present. However, because of the obstruction, the response, in terms of ventilation and the oxygen cost of this ventilation, will be altered. It is therefore proposed that incremental changes in total mechanical work are a more accurate gauge of the response of the respiratory apparatus to carbon dioxide than are increments of ventilation or oxygen consumption.

It should be pointed out that while resting $\mathrm{pCO}_{2}$ and ventilation were unchanged during obstructed breathing, the total mechanical work at rest was increased. If total mechanical work is a better gauge of the activity of the respiratory system, this suggests that a given stimulus was producing a greater response during resting obstructed breathing. Thus, this would represent an increase in activity of the respiratory center when the subject was breathing through an obstruction.

The conclusions reached in this paper are dependent on certain assumptions which are inherent in the methods of determining the oxygen cost, and the efficiency, of the muscles of respiration. It is assumed that the efficiency with which the respiratory apparatus handles added work loads is similar to its efficiency without added work loads, at rest or at low levels of ventilation, and during isometric contraction. The interpretation of the data presented is valid, therefore, only within the limits of these assumptions.

\section{SUM MARY AND CONCLUSION}

1. The respiratory response to carbon dioxide was assessed in 12 normal and 10 emphysematous subjects.

2. Evidence is presented to suggest that incremental changes in total mechanical work are a more accurate gauge of the respiratory response to carbon dioxide than are increments of ventilation or oxygen consumption.

3 . The response of the respiratory center and muscles of patients with emphysema, when measured in terms of total mechanical work done, is lower than that of normal subjects.

4. The response of the emphysematous subjects with carbon dioxide retention at rest while breathing room air, tends to be depressed below that of the patients who were normocapnic.

\section{REFERENCES}

1. Alexander, J. K., West, J. R., Wood, J. A., and Richards, D. W. Analysis of the respiratory response to carbon dioxide inhalation in varying clinical states of hypercapnia, anoxia, and acidbase derangement. J. clin. Invest. 1955, 34, 511.

2. Donald, K. W., and Christie, R. V. The respiratory response to carbon dioxide and anoxia in emphysema. Clin. Sci. 1949, 8, 33.

3. Prime, F. J., and Westlake, E. K. The respiratory response to $\mathrm{CO}_{2}$ in emphysema. Clin. Sci. 1954, 13, 321.

4. Cherniack, R. M., and Snidal, D. P. The effect of obstruction to breathing on the ventilatory respone to $\mathrm{CO}_{2}$. J. clin. Invest. 1956, 35, 1286.

5. Campbell, E. J. M., Westlake, E. K., and Cherniack, R. M. Simple methods of estimating oxygen consumption and efficiency of the muscles of breathing. J. appl. Physiol. 1957, 11, 303.

6. Cherniack, R. M. The oxygen consumption and efficiency of the respiratory muscles in health and emphysema. J. clin. Invest. 1959, 38, 494.

7. Campbell, E. J. M., Westlake, E. K., and Cherniack, R. M. The oxygen consumption and efficiency of the respiratory muscles of young male subjects. Clin. Sci. 1959, 18, 55.

8. Rahn, H., and Otis, A. B. Continuous analysis of alveolar gas composition during work, hyperpnea, hypercapnia and anoxia. J. appl. Physiol. 1949, 1, 717.

9. Riley, R. L., Proemmel, D. D., and Franke, R. E. A direct method for determination of oxygen and carbon dioxide tensions in blood. J. biol. Chem. $1945,161,621$.

10. Brinkman, G. L., Johns, C. J., Donoso, H., and Riley, R. L. A modification of the method of Riley, Proemmel and Franke for determination of oxygen and carbon dioxide tensions in blood. J. appl. Physiol. 1954, 7, 340.

11. Richards, D. W., Fritts, H. W., Jr., and Davis, A. L. Observations on the control of respiration in emphysema: The effects of oxygen on ventilatory response to $\mathrm{CO}_{2}$ inhalation. Trans. Ass. Amer. Phycns 1958, 71, 142. 